\title{
Author Correction: Surface properties of SAR11 bacteria facilitate grazing avoidance
}

Ayelet Dadon-Pilosof, Keats R. Conley, Yuval Jacobi, Markus Haber, Fabien Lombard, Kelly R. Sutherland, Laura Steindler, Yaron Tikochinski, Michael Richter, Frank Oliver Glöckner, Marcelino T. Suzuki, Nyree J. West, Amatzia Genin and Gitai Yahel

Correction to: Nature Microbiology https://dx.doi.org/10.1038/s41564-017-0030-5 (2017); published online 2 October 2017.

In the version of this Letter originally published, the authors incorrectly stated that primers $28 \mathrm{~F}-519 \mathrm{R}$ were reported in ref. 54 to underestimate the abundance of SAR11 in the ocean. This statement has now been amended in all versions of the Letter.

Published online: 20 October 2017

https://doi.org/10.1038/s41564-017-0064-8 